\title{
Application of Sodium Dodecyl Sulfate Coated Iron Oxide Magnetic Nanoparticles for the Extraction and Spectrofluorimetric Determination of Propranolol in Different Biological Samples
}

\author{
Ahad Bavili Tabrizi*1,2 and Nadereh Dehghani Teymurlouie ${ }^{3,4}$ \\ 1 Biotechnology Research Center, Tabriz University of Medical Sciences, Tabriz, Iran. \\ 2 Department of Medicinal Chemistry, Faculty of Pharmacy, Tabriz University of Medical Sciences, Tabriz, Iran. \\ 3 Drug Applied Research Center, Tabriz University of Medical Sciences, Tabriz, Iran. \\ 4 Department of Chemistry, Payame Noor University, Tehran, Iran, P. O. Box 19395-3697. \\ * Dr. Ahad Bavili Tabrizi. Associate Professor of Analytical Chemistry, Dept. of Medicinal Chemistry, \\ Faculty of Pharmacy \& Biotechnology Research Center. Tabriz University of Medical Sciences. \\ Tabriz, Iran. Tel.: +98-41-33372250. Fax: +98-41-33344798 \\ E-mail: a.bavili@tbzmed.ac.ir, abavilitabrizia@gmail.com
}

Received November $25^{\text {th }}, 2015$; Accepted June $12^{\text {th }}, 2016$.

\begin{abstract}
A new analytical approach was developed involving magnetic solid-phase extraction (MSPE) and spectrofluorimetric determination of propranolol (PRO) in biological fluids. A urine or plasma sample was prepared and adjusted to $\mathrm{pH} 3-4$, then PRO was quickly extracted using $\mathrm{Fe}_{3} \mathrm{O}_{4}$ magnetic nanoparticles (MNPs) modified by the surfactant sodium dodecyl sulfate (SDS) and determined applying spectrofluorimetry. Experimental conditions, such as the amount of MNPs and SDS, $\mathrm{pH}$ value, standing time, desorption solvent and maximal extraction volume have been adjusted to optimize the extraction process and to obtain analytical characteristics of the method. Linearity was observed in the analyte's concentration range of $2-75 \mathrm{ng} \mathrm{mL}^{-1}$ for both urine and plasma samples. The correlation coefficients (r) were higher than 0.99 . The method showed good precision and accuracy, with intra- and inter-assay precisions of less than $5.0 \%$ at all concentrations. Standard addition recovery tests were carried out, and the recoveries ranged from $79.4 \%$ to $90.4 \%$. The limits of detection and quantification were 0.85 and $2.80 \mathrm{ng} \mathrm{mL}^{-1}$, respectively, for urine and 0.74 and $2.43 \mathrm{ng} \mathrm{mL}^{-1}$, respectively, for plasma. The method was applied to the determination of PRO in human urine and plasma samples.
\end{abstract}

Key words: Biological samples; $\mathrm{Fe}_{3} \mathrm{O}_{4}$ magnetic nanoparticles; Propranolol; Solid phase extraction; Spectrofluorimetry.

\section{Introduction}

Propranolol, 1-[isopropylamino-3-[1-naphthyloxy]-2-propanol], is a $\beta$-adrenoceptor antagonist ( $\beta$-blocker) (PRO), which is widely used in the treatment of several diseases such as cardiac arrhythmia, angina pectoris, sinus tachycardia, thyrotoxicosis, hypertrophic subaortic stenosis and hypertension [1]. It is also used in low activity sports, reducing cardiac frequency, contraction force and coronary flow. Therefore, it has been included in the list of forbidden substances by the International
Resumen. Se ha desarrollado un nuevo procedimiento analítico que implica la extracción magnética en fase sólida (MSPE magnetic solid phase extraction) y la determinación espectrofluorimétrica de propranolol (PRO) en fluidos biológicos. En la preparacion de muestras de plasma sanguínea u orina, se ajustó el $\mathrm{pH}$ 3-4 e inmediatamente se llevó a cabo la extracción del PRO empleando nanopartículas $\mathrm{Fe} 3 \mathrm{O} 4$ (MNPS) modificadas con dodecilsulfato de sodio (SDS). Las condiciones de extracción tales como la cantidad de MNPS y SDS, el valor de $\mathrm{pH}$, el tiempo de extracción, el tipo y volumen de disolvente en la etapa de desorción, han sido establecidas experimentalmente y en estas condiciones finales se evaluaron principales características analíticas del método. El intervalo de linealidad cubrió las concentraciones del analito de 2-75 $\mathrm{ng} \mathrm{mL}^{-1}$ tanto para la orina como para el plasma. Los coeficientes de correlación (r) fueron superiores a 0.99. El método mostró una buena precisión y exactitud, con desviación estándar relativa intra- e inter-ensayo de menos de $5.0 \%$ en todo el intervalo de linealidad. En los experimentos de adición de estándar, se obtuvieron porcentajes de recuperación entre 79.4\% y 90.4\%. Los límites de detección y de cuantificación fueron 0.85 y $2.80 \mathrm{ng} \mathrm{mL}^{-1}$ para la orina y 0.74 y $2.43 \mathrm{ng} \mathrm{mL}^{-1}$ para el plasma, respectivamente. El método se utilizó para la determinación de propranolol en muestras de orina y plasma de humanos.

Palabras clave: Muestras biológicas; Nanopartículas magnéticas Fe3O4; Propranolol; Extracción en fase sólida; Espectrofluorimetría.

Olympic Committee [1,2]. Monitoring of PRO in biological fluids is important not only in clinical practice but also in the field of doping control.

PRO is a highly lipophilic substance and is almost completely absorbed following oral administration. However, most of the drug is metabolized in the liver during its first passage through the portal circulation, on average, about $25 \%$ reach the systemic circulation [3]. Plasma concentrations encountered during PRO therapy may range from a low of $1 \mathrm{ng} \mathrm{mL}^{-1}$ to above $100 \mathrm{ng} \mathrm{mL}^{-1}[3,4]$. 
Several methods including high performance liquid chromatography (HPLC) [5-8],gas chromatography (GC) [9], GC-mass spectrometry (MS)[9], HPLC-MS [3,10,11], electrophoresis $[12]$ and fluorimetry $[1,2,13]$, have been reported for the determination of PRO in biological fluids. PRO showed strong native fluorescence signals at acidic $\mathrm{pH}$ but in alkaline media its fluorescent was decreased. Also, fluorescence intensities of PRO in SDS micellar media are 2.4 times higher than those in water media, whereas TX-100 caused a decrease in the fluorescence intensity of the sample [13].

Using a liquid-liquid extraction (LLE) [5,6,9-11] or SPE $[3,7,12]$ step prior to the instrumental separation and determination of analytes in biological samples has been widely used and reported in literature, because it enables the elimination of the interferences present in the urine and the concentration of the analytes. LLE methods require large amounts of organic solvents, which are harmful to humans and the environment. SPE methods have several advantages when compared with the other sample preparation techniques, including the easily of automation, more efficient separation of interferences from analytes, reducing organic solvent consumption, and more efficient in analyte recovery. Although, potential variability of SPE packing, ir-reversible adsorption of some analytes on SPE cartridges, and more complex method development are some of the drawbacks of this technique [14].

Recently, MSPE methods based on modification of MNPs with some ionic surfactants have been proposed for the preconcentration of a variety of organic [15-23] and inorganic compounds from various matrices [24-27]. In these SPE methods, ionic surfactants such as SDS or cetyltrimethylammonium bromide (CTAB) were adsorbed on the surface of magnetite and/or modified MNPs with silica and alumina [16-19,22-27]. Covering the surfaces of MNPs with surface active agents can improve the sorption capacity and efficiency of the extraction. The hydrophobic layers on the surface of MNPs provide suitable conditions for nonpolar components to interact with MNPs [24].

By using the MNPs modified with surfactants the limitations of microparticle sorbent can be overcome including relatively low extraction capability and time-consuming extractions with large volume samples. As a result, the use of MSPE with surfactant coated MNPs has a number of advantages, such as high extraction yields, high break through volumes and easy elution of analytes and regeneration of sorbent $[15,16,20]$. Moreover, high surface area of MNPs can improve the sorption capacity of analytes, as well as the strong magnetism of MNPs reduce the analysis time through the rapid isolation of MNPs with a strong magnet from large volumes of the sample solution.

In the present work, MNPs coated by SDS were synthesized according to the literature [23] and employed as new sorbent in MSPE of PRO, for the first time. The complex biological samples were cleaned-up by the proposed MSPE method and the extracted analyte determined with a simple and low-cost spectrofluorimetric method. In this method the sample preparation time is dramatically decreased by the fact that MNPs dispersed in the bulk solution, and as a result, extraction can be achieved very quickly by using magnet. Thus, biological samples can be prepared in a more safe and time-consuming manner along with sensitive, selective and low cost spectrofluorimetric determination of PRO.

\section{Experimental}

\section{Apparatus}

All fluorescence measurements were made using a Shimadzu RF-5301 PC spectrofluorophotometer equipped with a $150 \mathrm{~W}$ Xenon lamp and $1.00 \mathrm{~cm}$ quartz cells. Instrument excitation and emission slits both were adjusted to $3 \mathrm{~nm}$. FT-IR spectra were recorded using a FT-IR spectrometer, Tensor 27 (Bruker Optik GmbH, Rudolf-Plank-Str. 27, 76275 Ettlingen, Germany). A centrifuge from Hettich (EBA 20 model/ Andreas Hettich $\mathrm{GmbH} \&$ Co. KG, Tuttlingen, Germany) with $15 \mathrm{~mL}$ calibrated centrifuge tubes (Hirschmann, EM techcolor, Germany) was used to accelerate the phase separation process. The pH-meter model M120 (Halstead, Essex, England CO9 2DX) supplied with a glass combined electrode was used for the $\mathrm{pH}$ measurements. The mixtures were shacked using a Unimax 1010 Shaker-Inkubator (Heidolph, Germany).

\section{Materials}

Chemicals including iron (II) chloride tetrahydrate $\left(\mathrm{FeCl}_{2} \cdot 4 \mathrm{H}_{2} \mathrm{O}\right)$, iron (III) chloride hexahydrate $\left(\mathrm{FeCl}_{3} \cdot 6 \mathrm{H}_{2} \mathrm{O}\right)$, SDS, ethanol $(\mathrm{EtOH})$, methanol $(\mathrm{MeOH})$, sodium chloride $(\mathrm{NaCl})$, acetonitrile $(\mathrm{ACN})$, hydrochloric acid $(\mathrm{HCl})$, sodium hydroxide $(\mathrm{NaOH})$ and ethylenediaminetetraacetic acid (EDTA) disodium salt dehydrate were obtained from E. Merck (Darmstadt, Germany).

A stock solution of $500 \mu \mathrm{g} \mathrm{mL} L^{-1}$ of PRO was prepared by dissolving appropriate amount of pure drug (gifted by Hakim Pharm. Co. Tehran, Iran) in EtOH and was kept away from the light in a refrigerator at approximately $4^{\circ} \mathrm{C}$. Working standard solutions were obtained by appropriate dilution of this stock standard solution. All other reagents were of analytical reagent grade or higher. Ultrapure water (Milli-Q Advantage A 10 system, Millipore) was used throughout the work.

\section{Preparation of MNPs}

MNPs were prepared by the co-precipitation method [27] with some modifications [23]. According to our previous work, different conditions for the synthesis of MNPs were investigated and it was found the quality of MNPs were fully reproducible once the synthesis is performed using chloride salts, the $\mathrm{Fe}^{2+}$ / $\mathrm{Fe}^{3+}$ ratio fixed at $1: 1.7$ and addition of $\mathrm{Fe}^{2+} / \mathrm{Fe}^{3}$ mixture to $\mathrm{NaOH}$ solution (heated at $80^{\circ} \mathrm{C}$ ).

For this purpose, $4.6 \mathrm{~g}$ of $\mathrm{FeCl}_{3} \cdot 6 \mathrm{H}_{2} \mathrm{O}, 2.0 \mathrm{~g}$ of $\mathrm{FeCl}_{2} \cdot 4 \mathrm{H}_{2} \mathrm{O}$, and $0.85 \mathrm{~mL}$ of $\mathrm{HCl}\left(12 \mathrm{~mol} \mathrm{~L}^{-1}\right)$ were dissolved in $25 \mathrm{~mL}$ of deionized water which was degassed with $\mathrm{N}_{2}$ before use. The resulted clear yellowish green solution was added drop-wise into $250 \mathrm{~mL}$ of $1.5 \mathrm{~mol} \mathrm{~L}^{-1} \mathrm{NaOH}$ solution (heated to $80^{\circ} \mathrm{C}$ ), 
under vigorous stirring with $\mathrm{N}_{2}$ passing continuously through the solution during the reaction. Upon addition, the solution turned black and was then stirred magnetically at $1000 \mathrm{rpm}$ for $30 \mathrm{~min}$. After the reaction, the obtained precipitate was separated from the reaction medium by magnetic field, washed with $200 \mathrm{~mL}$ of deionized water four times, and then re-suspended in $250 \mathrm{~mL}$ of deionized water. The concentration of MNPs in this solution was found to be $1 \% \mathrm{w} / \mathrm{v}$. Our results showed that MNPs can be used twice after elution with $2.5 \mathrm{~mL}$ of deionized water and without any effect on their extraction ability.

\section{Procedure for biological samples}

The samples were treated based on reported methods with some modification [17,28]. Urine samples were obtained from a healthy male volunteer who took a single oral dose of a commercially available tablet (Rouz Daru) containing 20 mg PRO. The urine samples were collected over specified time intervals $\left(0-1,1-2 \frac{1}{2}, 2 \frac{1}{2}-4,4-6,6-8,8-10\right.$ and 10-12 h) after the oral administration of the tablet, and the samples were stored at $-4{ }^{\circ} \mathrm{C}$ until they were analyzed. The sample was centrifuged for $15 \mathrm{~min}$ at $4000 \mathrm{rpm}$ (i.e., $0.8 \mathrm{~kg} \mathrm{dm}^{-3}$ ). Afterwards, $0.5 \mathrm{~mL}$ aliquots of the supernatant solutions were spiked with PRO at proper concentration range and subjected to the general procedure described below.

Drug-free plasma samples were obtained from the Blood Transfusion Organization (BTO) in Tabriz, Iran, and stored at $-20{ }^{\circ} \mathrm{C}$ until they were analyzed. This sample named as quality control (QC) samples. Three hours after the administration of the tablet to a healthy volunteer, $10 \mathrm{~mL}$ blood sample was taken in a tube containing EDTA. After centrifugation, the plasma was removed and frozen at $-20{ }^{\circ} \mathrm{C}$ before use. A frozen plasma sample was thawed at room temperature and a $3 \mathrm{~mL}$ aliquot was transferred into a $15 \mathrm{~mL}$ centrifuge tube, spiked with PRO at proper concentration range and then $3 \mathrm{~mL}$ of $\mathrm{ACN}$ added to this sample to precipitate the proteins. The contents of the tube were mixed and centrifuged for $10 \mathrm{~min}$ at $4000 \mathrm{rpm}$, then $1.0 \mathrm{~mL}$ of the clear supernatant was transferred to another flask, and the general procedure described below was followed.

\section{Procedure for MSPE}

A 0.5 or $1.0 \mathrm{~mL}$ aliquot of prepared urine or plasma sample, respectively, was placed in an Erlenmeyer flask $(\mathrm{V}=250 \mathrm{~mL})$ and spiked with PRO, to give a concentration in the range 2.0$75.0 \mathrm{ng} \mathrm{mL}^{-1}$. The sample was then mixed with $2.0 \mathrm{~mL}$ of $1.0 \%$ $\mathrm{w} / \mathrm{v}$ MNPs solution and $13.0 \mathrm{~mL}$ of $1.0 \% \mathrm{w} / \mathrm{v}$ SDS solution. The solution was diluted to approximately $140 \mathrm{~mL}$ and $\mathrm{pH}$ was adjusted to 3 to 4 by addition of $0.1 \mathrm{~mol} \mathrm{~L}^{-1} \mathrm{HCl}$ solution, then the volume of the mixture was made up to $150 \mathrm{~mL}$ with ultra-pure water. The flask was shaked at $200 \mathrm{rpm}$ and allowed to complete the extraction process for $10 \mathrm{~min}$. Subsequently, a strong magnet was placed at the bottom of the beaker, and the SDS-coated MNPs were isolated from the solution. After about $5 \mathrm{~min}$, the solution became limpid and supernatant solution was decanted. Finally, the preconcentrated target analyte was eluted from the isolated particles with $\mathrm{MeOH}(5.0 \mathrm{~mL})$ to desorb the target analyte with the aid of stirring at $200 \mathrm{rpm}$. Finally, the fluorescence intensity was measured at $337 \pm 3 \mathrm{~nm}$ with the excitation wavelength set at $230 \pm 3 \mathrm{~nm}$. A schematic illustration of steps involved in the synthesis of MNPs and MSPE of $\mathrm{PRO}$ has been given in scheme 1 .

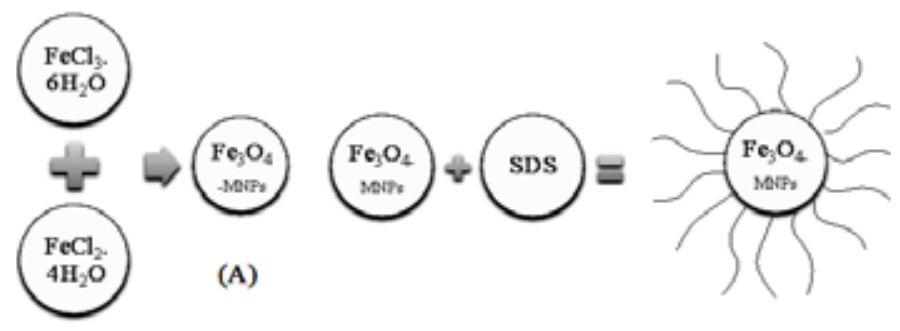

A 0.5 or $1.0 \mathrm{~mL}$ aliquot of prepared urin or plasma in $250 \mathrm{~mL}$ Erlenmeyer flask

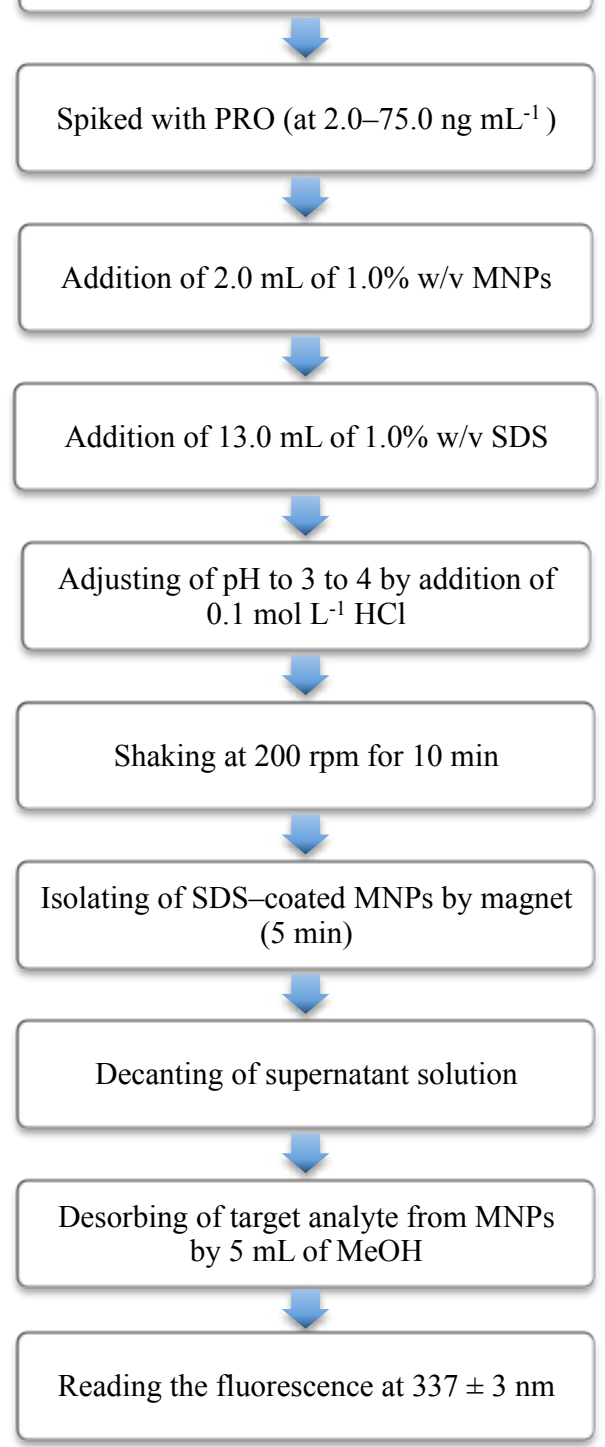

(B)

Scheme 1. A schematic illustration of steps involved in the synthesis of MNPs (A) and MSPE of PRO (B). 


\section{Results and Discussion}

The influences of different factors on the extraction conditions were studied. Fig. 1 shows the excitation and emission spectra for PRO extracted from aqueous or biological samples using the optimized MSPE conditions that were established.

\section{Characterization of MNPs}

The average particle size of obtained MNPs was less than $42 \mathrm{~nm}$ by using a SEM, model vega2 (Check Republic). Fig. 2 displays the IR spectrum of the $\mathrm{Fe}_{3} \mathrm{O}_{4}$ MNPs and the SDS coated $\mathrm{Fe}_{3} \mathrm{O}_{4}$ MNPs. Two characteristic bands can be distinguished in the IR spectrum of SDS coated $\mathrm{Fe}_{3} \mathrm{O}_{4}$ MNPs, while not observed in the $\mathrm{Fe}_{3} \mathrm{O}_{4}$ MNPs IR spectrum. Compared with the standard spectrum, the adsorption bands at 2923.2 and $2854.2 \mathrm{~cm}^{-1}$ could be attributed to the stretching vibration of $\mathrm{C}-\mathrm{H}$ band, as well as the adsorption band at $1224.6 \mathrm{~cm}^{-1}$ could be attributed to the stretching vibration of $\mathrm{S}=\mathrm{O}$ band, which showed that the surface of $\mathrm{Fe}_{3} \mathrm{O}_{4}$ MNPs was successfully modified with SDS.

\section{Effect of pH}

It is well known that the $\mathrm{pH}$ of the sample solution is one of the prime factors influencing the states of species (as ions or neutral forms) and adsorption behavior of a mixed hemimicelles system due to the different charge density of the $\mathrm{Fe}_{3} \mathrm{O}_{4}$ MNPs surface at the different working $\mathrm{pH}$ [15-17]. The point of zero charge (PZC) of $\mathrm{Fe}_{3} \mathrm{O}_{4}$ MNPs is about $6.5[17,27]$. When $\mathrm{pH}$ of

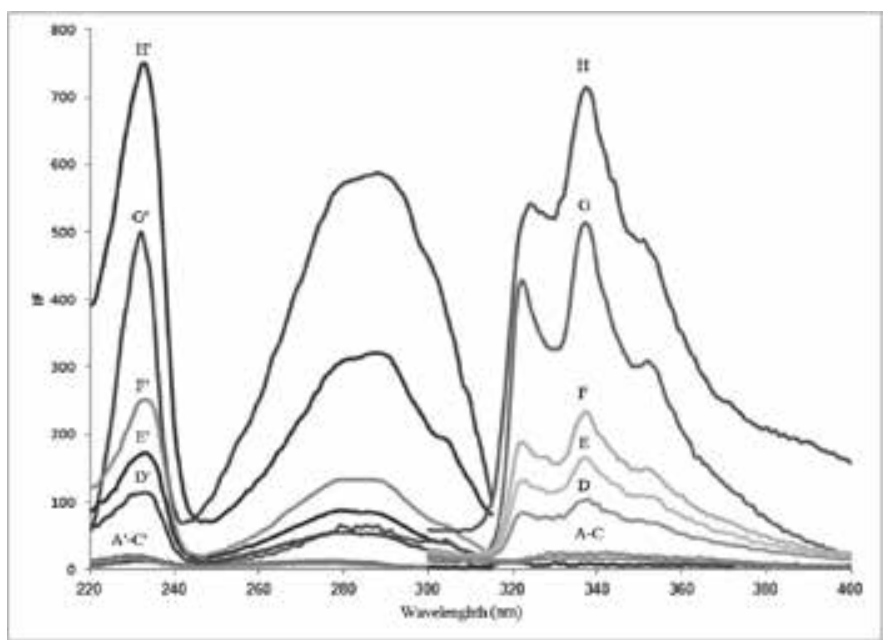

Fig. 1. Emission/excitation spectra after MSPE: (A\&A'), (B\&B'), (C\&C'): reagent's, urine and plasma blank, respectively; (D\&D') collected urine sample; (E\&E'): collected plasma sample (both after administration of PRO to one volunteer); (F\&F'): sample (D) spiked with PRO at $25 \mathrm{ng} \mathrm{mL}^{-1}$ concentration level; (G\&G') sample (E) spiked with PRO at $50 \mathrm{ng} \mathrm{mL}^{-1}$ concentration level; (H\&H') standard

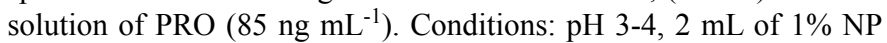
solution, $13 \mathrm{~mL}$ of $1 \%$ SDS solution, desorption with $5 \mathrm{~mL}$ of $\mathrm{MeOH}$ for $5 \mathrm{~min}$, other conditions have been mentioned in the text.

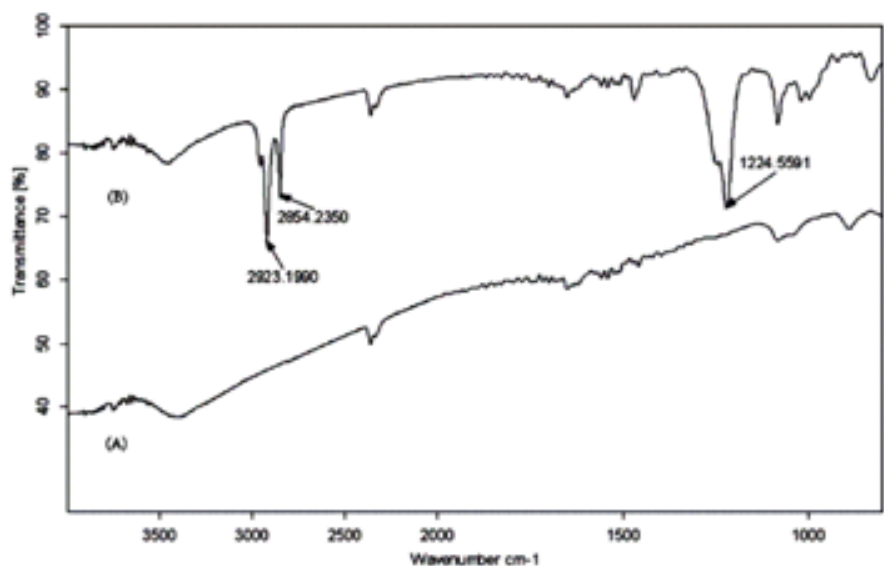

Fig. 2. IR spectrum of the $\mathrm{Fe}_{3} \mathrm{O}_{4} \mathrm{MNPs}(\mathrm{A})$ and the SDS coated $\mathrm{Fe}_{3} \mathrm{O}_{4}$ MNPs (B).

the solution is above its PZC, the surface of $\mathrm{Fe}_{3} \mathrm{O}_{4}$ MNPs is negatively charged. Oppositely, the surface of $\mathrm{Fe}_{3} \mathrm{O}_{4} \mathrm{NPs}$ is positively charged. The positively charged surface of $\mathrm{Fe}_{3} \mathrm{O}_{4}$ MNPs in acidic solutions was favorable for the adsorption of anionic surfactants and thus targeted analyte [15].

In this study, the effect of $\mathrm{pH}$ was examined by varying $\mathrm{pH}$ between 1.0 and 9.0. As shown in Fig. 3, with the increase of $\mathrm{pH}$ value, the PRO adsorption amounts increased remarkably, so the maximum adsorption was achieved at $\mathrm{pHs}$ between 3 to 5 , then decreased at higher $\mathrm{pH}$ values. This can be attributed to the fact that when the $\mathrm{pH}$ was below its $\mathrm{PZC}$, the $\mathrm{Fe}_{3} \mathrm{O}_{4}$ MNPs surface was positively charged and the negative ions of SDS can be adsorbed to the $\mathrm{Fe}_{3} \mathrm{O}_{4}$ MNPs surface to form mixed hemimicelles and adsorb targeted analyte. When $\mathrm{pH}$ was above the isoelectric point of the $\mathrm{Fe}_{3} \mathrm{O}_{4}$ MNPs, the positive charge density on the surface of the $\mathrm{Fe}_{3} \mathrm{O}_{4}$ MNPs is decreased, thus the adsorption of SDS molecules on NPs surfaces becomes less favorable and this could lead to a remarkable depression in the analytical signal. On the other hand, in quite acidic medium, the analytical signal was decreased probably due to dissolution of $\mathrm{Fe}_{3} \mathrm{O}_{4}$ MNPs at $\mathrm{pH}_{\mathrm{s}}$ below 2.0 or protonation of SDS molecules, which could reduce the hemimicelles formation efficiency $[15,17]$. Thus pHs between 3.0 to 4.0 was chosen for all subsequent experiments and $\mathrm{HCl}$ solution used for the $\mathrm{pH}$ adjustment.

\section{The amounts of MNPs and sample volume}

Compared to ordinary sorbents (micron-size particle sorbents), NP sorbents have higher surface areas. Therefore, satisfactory results can be achieved with fewer amounts of NP sorbents $[17,24]$. The influence of MNPs content was studied by adding different amounts of MNPs suspension, ranging from 0.25$5.0 \mathrm{~mL}$. It can be seen from Fig. 4 that the highest (and approximately consistent) fluorescence intensities were found when 2.0-5.0 $\mathrm{mL}$ of MNPs suspension $(1 \% \mathrm{w} / \mathrm{v})$ was used. Therefore, $2.0 \mathrm{~mL}$ of NP suspension was selected as the optimum for use in later tests. 
The effect of solution volume on the enrichment of PRO was examined by extraction different volumes (in the range 50$200 \mathrm{~mL}$ ) of aqueous solutions spiked with a fixed mass of PRO (e.g. $5 \mu \mathrm{g}$ ) in the optimal conditions. The results (e.g. Fig.5) showed that the analyte present in the volumes up to $150 \mathrm{~mL}$ was completely and quantitatively adsorbed with NPs. Thus, $150 \mathrm{~mL}$ was considered to be the maximal enrichment volume for water samples.

\section{Effect of SDS amount}

The outer surface of hemimicelles is hydrophobic whereas that of admicelles is ionic, which provides different mechanisms for retention of organic compounds and both are suitable for the SPE method. In mixed hemimicelles phase, the adsorption is driven by both hydrophobic interactions and electrostatic attraction because of the formation of hemimicelles and admicelles on the surface of mineral oxides [19,20]. From Fig. 6, it was observed that MNPs can't adsorb PRO from aqueous solution at all, while their SDS modified form adsorbed PRO

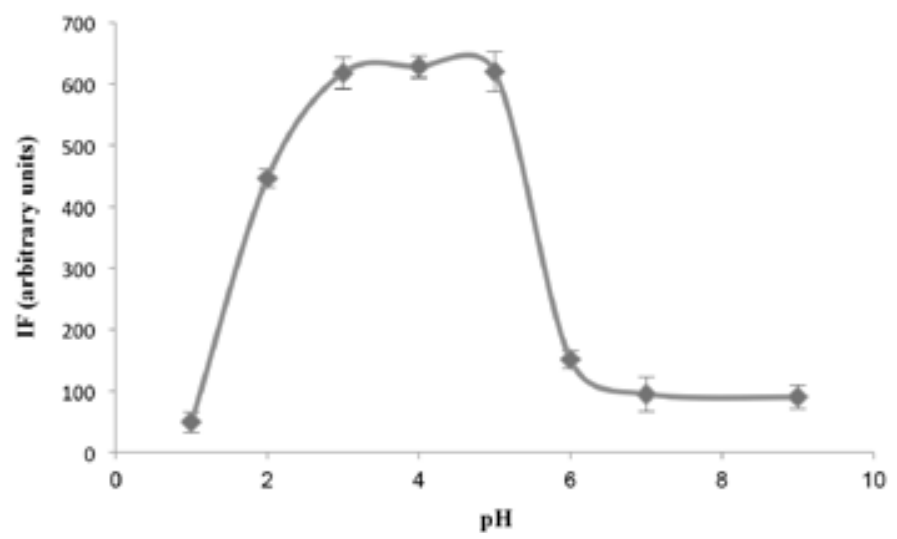

Fig. 3. The effect of $\mathrm{pH}$ on the analytical signal for $75 \mathrm{ng} \mathrm{mL}^{-1} \mathrm{PRO}$. The conditions were the same as shown for Fig. 1. Each point corresponds to the average of three measurements and standard deviation has been added as error bars.

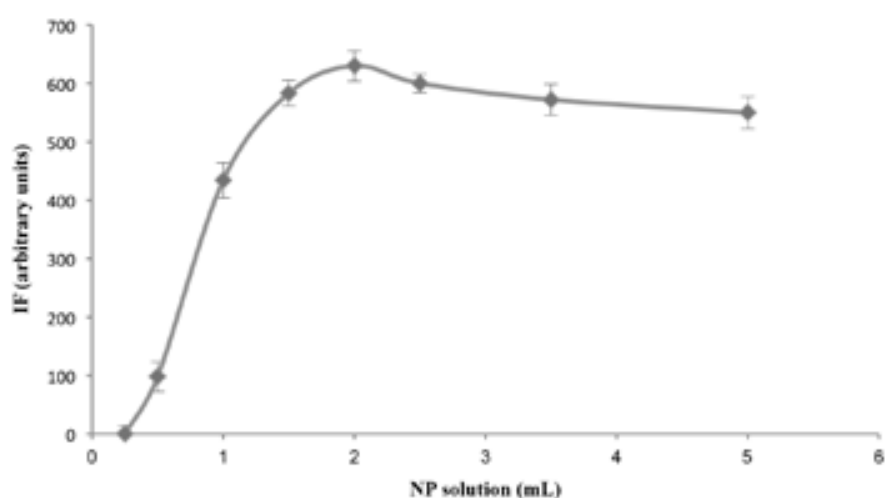

Fig. 4. The effect of NP amount on the analytical signal for $75 \mathrm{ng} \mathrm{mL}^{-1}$ PRO. The conditions were the same as shown for Fig. 1. Each point corresponds to the average of three measurements and standard deviation has been added as error bars. efficiently. In this study, SDS was added to the solution at concentrations lower than its CMC $\left(2.3 \mathrm{~g} \mathrm{~L}^{-1}\right.$, e.g. $\left.7.98 \mathrm{mM}\right)$ [29] to modify the surface of $\mathrm{Fe}_{3} \mathrm{O}_{4} \mathrm{NPs}$. The adsorption amount of PRO increased remarkably with the increasing amount of SDS. The increase in adsorption can be explained by the gradual formation of SDS aggregates on the $\mathrm{Fe}_{3} \mathrm{O}_{4}$ MNPs surface and the $\mathrm{PRO}$ is adsorbed gradually. Maximum adsorption was obtained when SDS amounts were between 3 and $4 \mathrm{mM}$. When SDS amount was above $4 \mathrm{mM}$, the adsorption of the analyte decreased gradually, which may be attributed to the fact that the SDS molecules began to form micelles in the bulk to the fact aqueous solution and the micelles caused the PRO to redistribute into the solution again. Given these findings, $13 \mathrm{~mL}$ of $1 \%$ SDS solution (final concentration of $3 \mathrm{mM}$ ) was selected for next studies.

\section{Extraction and desorption time}

In order to realize complete extraction, the effect of standing time on the sorption and desorption was investigated. The

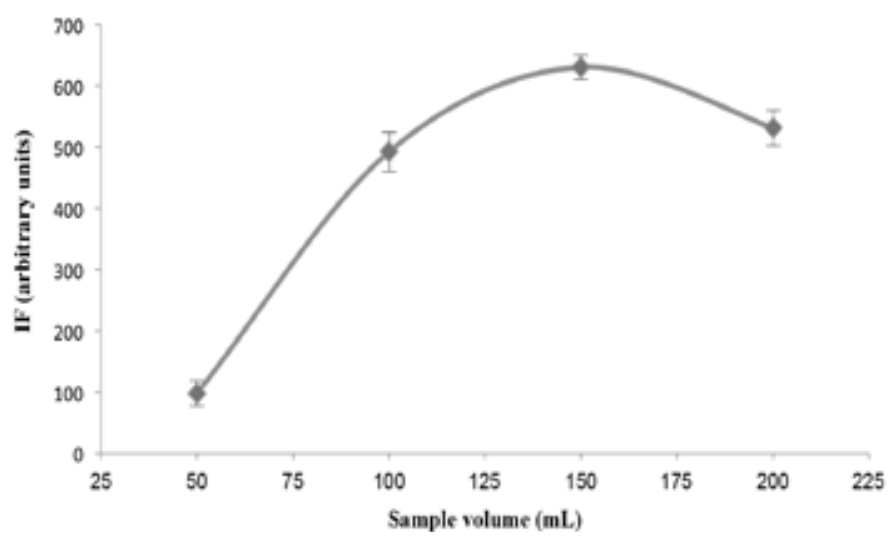

Fig. 5. The effect of sample volume on the analytical signal for $75 \mathrm{~mL}^{-1}$ PRO. The conditions were the same as shown for Fig. 1. Each point corresponds to the average of three measurements and standard deviation has been added as error bars.

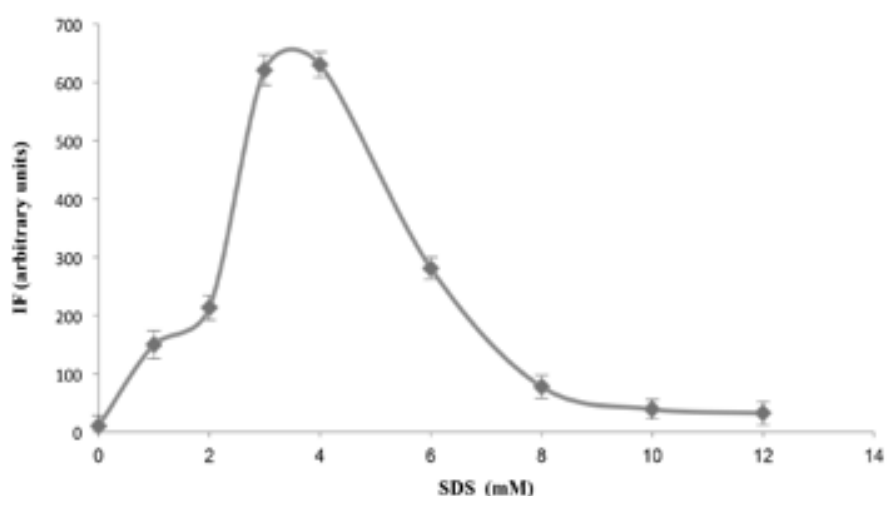

Fig. 6. The effect of SDS amount on the analytical signal for $75 \mathrm{~mL}^{-1}$ PRO. The conditions were the same as shown for Fig. 1. Each point corresponds to the average of three measurements and standard deviation has been added as error bars. 
extraction and desorption time profiles were studied by varying the mixing time of MNPs-sample suspension in the range of 2-20 min. Thus, experimental results showed that a shaking time of 10 and 5 min were sufficient for achieving satisfactory sorption and desorption of targeted analyte, respectively. The high surface area of MNPs along with homogeneous distribution of the nanosorbent throughout the sample and its superparamagnetic properties could be the possible reasons for achieving such a fast extraction process $[17,20]$.

\section{Desorption condition}

Organic solvents can rapidly and completely disrupt the mixed hemimicelles and therefore the analyte is removed from the surface of NPs $[18,19]$. Various desorbing eluents including $\mathrm{MeOH}$, EtOH, acidified (Ac) $\mathrm{MeOH}$ or EtOH, acetone (AC) and $\mathrm{ACN}$ were used to find the best desorbing solvent for the adsorbed PRO. Their effect on the fluorescence intensity of PRO is shown in Fig. 7. As can be seen from this Fig., the best elution efficiency was obtained when $\mathrm{MeOH}$ was used, probably due to its best desorption ability. The MNPs were eluted with different volumes of $\mathrm{MeOH}$ such as $2.5 \mathrm{~mL}, 5 \mathrm{~mL}$ and $2 \times 2.5 \mathrm{~mL}$. It was found the elution with $5 \mathrm{~mL}$ volume of $\mathrm{MeOH}$ was sufficient for quantitative elution of the retained analyte.

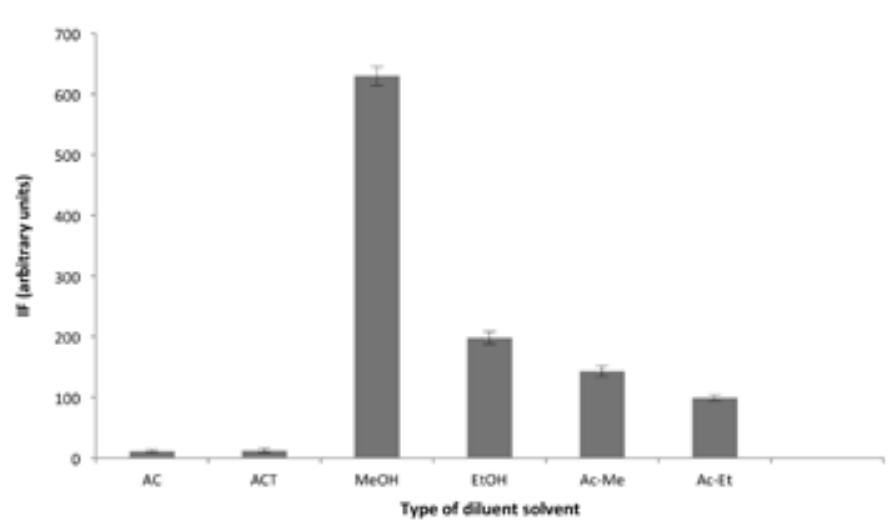

Fig. 7. The effect of the desorbing solvent on the analytical signal for $75 \mathrm{ng} \mathrm{mL}^{-1}$ PRO. The conditions were the same as shown for Fig. 1. In each case the MNPs was eluted with $5.0 \mathrm{~mL}$ of each solvent. Each point corresponds to the average of three measurements and standard deviation has been added as error bars.

\section{The validation of the method}

The method was validated according to guidelines set by the FDA [30] and considering the linearity, sensitivity, precision, accuracy and recovery effect in order to demonstrate the feasibility of the present approach for the determination of PRO in human urine and plasma.

The calibration curves were obtained for standard aqueous or pooled urine and plasma samples spiked with PRO. These curves were established by measuring the fluorescence intensity of eleven or six solutions of various concentrations of PRO in standard aqueous or biological samples, respectively. In all cases linear relations between fluorescence intensity and concentration of PRO was found in the range $1-100 \mathrm{ng} \mathrm{mL}^{-1}$ and 2-75 $\mathrm{ng} \mathrm{mL}^{-1}$ for standard aqueous or biological samples, respectively. The equations, including standard deviations for slopes and correlation coefficients for the calibration curves, are summarized in Table 1. The LOD and LOQ were defined based on IUPAC definition [31] by considering the three and ten times the standard deviation of the blank signals $\left(\mathrm{S}_{\mathrm{b}}\right)$ and based on $3 \mathrm{~S}_{\mathrm{b}} / \mathrm{m}$ and $10 \mathrm{~S}_{\mathrm{b}} / \mathrm{m}$ equations, respectively, where $\mathrm{m}$ is the slope of the calibration line. The differences in the slopes of calibration curves can be attributed to the presence of some matrix effects, on the other hand the different LODs and LOQs are due to different standard deviations as well as different slopes.

The precision of the method was measured through intra-day and inter-day precision and expressed as the relative standard deviation (\%RSD). Intra-day precision was evaluated by analyzing $\mathrm{QC}$ samples in three concentration range (e.g. low, medium and high) in the same day 5 replicates. The inter-day precision was assessed by duplicate analyzing, during three consecutive days, at the same concentration levels. Good precision was achieved with RSD values lower than $3.6 \%$ for intra-day and 5.0\% for inter-day precision (Table 2). The accuracy, expressed as the relative error (\%), was better than $6.2 \%$.

\section{The accuracy of the proposed method and interference study}

The PRO recoveries were determined at three concentration levels. For this purpose drug-free urine and plasma were obtained from a healthy volunteer and from the BTO, respectively. The aliquot volumes of QC samples were spiked with PRO at the three test concentrations and then treated as described in

Table 1. Analytical characteristics of the proposed method.

\begin{tabular}{|c|c|c|c|c|c|c|}
\hline Sample & $\begin{array}{c}\text { Concentration } \\
\text { range } \\
\left(\mathrm{ng} \mathrm{mL}^{-1}\right)\end{array}$ & $\begin{array}{l}\text { Regression equation } \\
\qquad(\mathrm{n}=3)^{*}\end{array}$ & $\mathrm{r}^{2}$ & $\mathrm{RSD}+\%$ & $\begin{array}{c}\text { LOD } \\
\left(\text { ng mL }{ }^{-1}\right)\end{array}$ & $\begin{array}{c}\text { LOQ } \\
\left(\mathrm{ng} \mathrm{mL}^{-1}\right)\end{array}$ \\
\hline Plasma & $2.0-75.0$ & $6.685( \pm 0.210) \mathrm{C}-0.146$ & 0.9910 & $2.51-4.52$ & 0.74 & 2.43 \\
\hline Urine & $2.0-75.0$ & $6.088( \pm 0.189) \mathrm{C}+9.609$ & 0.9912 & $1.83-4.98$ & 0.85 & 2.80 \\
\hline Water & $1.0-100.0$ & $8.154( \pm 0.235) \mathrm{C}+7.092$ & 0.9956 & $1.55-3.65$ & 0.42 & 1.25 \\
\hline
\end{tabular}

$*$ These values are slope \pm S.D $(n=3)$ on a same day.

$\dagger \mathrm{RSD}$ has been reported for intra-day precision. 
Table 2. Intra- and inter-day precisions and accuracies for determination of PRO.

\begin{tabular}{|c|c|c|c|c|c|}
\hline \multirow[b]{2}{*}{ Sample } & \multirow{2}{*}{$\begin{array}{l}\text { Nominal C* } \\
\quad\left(n g \mathrm{~mL}^{-1}\right)\end{array}$} & \multicolumn{2}{|c|}{$\begin{array}{c}\text { Precision } \\
\text { (RSD\%) }\end{array}$} & \multicolumn{2}{|c|}{$\begin{array}{c}\text { Accuracy } \\
\text { (R.E\%) }\end{array}$} \\
\hline & & Intra-day & Inter-day & Intra-day & Inter-day \\
\hline & 10.0 & 2.47 & 2.88 & +3.20 & -4.20 \\
\hline & 50.0 & 1.83 & 4.98 & -4.32 & -5.42 \\
\hline \multicolumn{6}{|l|}{ Plasma } \\
\hline & 50.0 & 2.51 & 4.22 & +2.62 & -6.20 \\
\hline
\end{tabular}

$* \mathrm{C}=$ concentration

$\mathrm{R} . \mathrm{E}=$ relative error defined as: $\mathrm{R} . \mathrm{E}=\frac{\text { obtained amount }- \text { Nominal } \mathrm{C}}{\text { Nominal } \mathrm{C}} \times 100$

the "Procedure for biological samples" section. Aliquots $(0.5$ $\mathrm{mL}$ ) of clear supernatant solutions of each test sample were transferred to clean flasks and analyzed following the optimized procedure. As can be seen in Table 3, the recoveries ranged from 79.4 to $86.8 \%$ and 84.3 to $90.4 \%$, for urine and plasma samples, respectively, and seem to be satisfactory. The evaluation of precision and accuracy was based on the criteria that the RSD of each concentration level should be within $\pm 15 \%$ of the nominal concentration [30]. Thus, the results (summarized in Tables 1-3), indicate that the method met the requirements of a bioassay.

Typical spectra for a PRO standard solution, blank urine and plasma, a urine and plasma sample from a volunteer, and the urine and plasma samples spiked with PRO are shown in Fig. 1. No additional peaks caused by interfering compounds were observed at the emission wavelength that was used in this work. Therefore, the similarities in the excitation and emission spectra, found for each sample, along with reasonable recoveries indicated that there were no significant matrix effects on this work.

As well as, the influence of frequently encountered excipients and additives on the proposed method was studied by adding different amounts of possible interference to aqueous sample containing $25 \mathrm{ng} \mathrm{mL}^{-1}$ of PRO. The tolerance limit was taken as the concentration causing an error of not more than $7 \%$

Table 3. Recoveries of PRO from spiked urine and plasma samples.

\begin{tabular}{lccc}
\hline \multicolumn{1}{c}{ Sample } & $\begin{array}{c}\text { Added } \\
\left(\mathrm{ng} \mathrm{mL}^{-1}\right)\end{array}$ & $\begin{array}{c}\text { Found } \pm \mathrm{SD}(\mathrm{n}=3) \\
\left(\mathrm{ng} \mathrm{mL}^{-1}\right)\end{array}$ & Recovery $(\%)$ \\
\hline Urine & & & \\
& 25.0 & $21.7 \pm 0.65$ & 86.8 \\
& 50.0 & $39.7 \pm 1.03$ & 79.4 \\
& 75.0 & $62.6 \pm 1.72$ & 83.5 \\
Plasma & & & \\
& 25.0 & $22.6 \pm 0.86$ & 90.4 \\
& 50.0 & $43.1 \pm 1.64$ & 86.2 \\
& 75.0 & $63.2 \pm 2.27$ & 84.3 \\
\hline
\end{tabular}

in the determination of the drug. No interference was observed from the presence of lactose, glucose, citrate, saccharose, starch, talk, magnesium stearate in the ratios commonly used in pharmaceutical preparations. Thus, the proposed method showed a high degree of tolerance for these species.

\section{Comparison with other extraction methods}

The performance of the proposed method was compared with the performances of other methods to highlight the advantages of the proposed method. The distinct features of the methods that were assessed are summarized in Table 4. The most significant feature of the proposed method is that the LOD achieved using the proposed method is superior to those obtained with sensitive methods such as HPLC [6,8], and HPLC-MS [3] and comparable to those obtained with other methods in Table 4. Compared with methods in which CE, HPLC or HPLC-MS are used to determine the target analyte, the proposed method does not require high levels of financial investment or involve high instrument maintenance costs. It is also evident that the dynamic linear range, precision and recoveries achieved using the proposed method are comparable to those achieved using other methods.

\section{The application of the method}

PRO is prohibited by the World Anti-doping Agency (WADA) in some sports. The minimum required performance limit of PRO for doping analysis laboratories is $0.5 \mu \mathrm{g} \mathrm{mL}^{-1}$ [33]. Also, plasma PRO levels higher than $20 \mathrm{ng} \mathrm{mL}^{-1}$; defined as minimum effective concentration; were sufficient to obtain a clinical response by $\beta$-adrenoceptor blockage [13]. These concentration levels can be simply monitored by our proposed method.

For this purpose, the proposed method was successfully used to determine PRO in human urine and plasma samples. The urine and plasma for this purpose was collected after PRO had been ingested and treated as described in the "Procedure for biological samples" section. The PRO concentration in the plasma sample was found to be $213.9 \mathrm{ng} \mathrm{mL}^{-1}$, which was in accordance with the results of other studies $[6,10,13]$. 
Table 4. Analytical characteristics of different methods used for extraction and determination of PRO.

\begin{tabular}{|c|c|c|c|c|c|c|c|}
\hline $\begin{array}{c}\text { Ex./determination } \\
\text { Method }\end{array}$ & Sample & $\begin{array}{c}\text { Concentration range } \\
\left(\mathrm{ng} \mathrm{mL}^{-1}\right)\end{array}$ & $\mathrm{r}$ & $\mathrm{RSD} \%$ & $\begin{array}{c}\text { LOD } \\
\left(\mathrm{ng} \mathrm{mL}^{-1}\right)\end{array}$ & $\begin{array}{c}\text { Mean recovery } \\
(\%)\end{array}$ & Ref. \\
\hline SPE/HPLC-MS & $\mathrm{P}$ & $0.2-135.0$ & 0.9995 & $0.30-3.6$ & 50.0 & 96.4 & 3 \\
\hline SIA-SPE/F & $\mathrm{P}$ & $1.0-75.0$ & 0.9999 & $0.54-4.0$ & 46.0 & $96.2-97.8$ & 7 \\
\hline CM-LPME/HPLC & $\mathrm{U}$ & $50.0-8000$ & 0.9998 & 5.9 & 5.0 & $97.9-99.3$ & 8 \\
\hline $\mathrm{SPE} / \mathrm{CZE}$ & $\mathrm{U}$ & $93.0-2000$ & 0.9952 & 1.5 & 28.0 & $99.7-109.0$ & 12 \\
\hline $\mathrm{SPME} / \mathrm{CE}$ & $\mathrm{U}$ & $50.0-10000$ & $0.9981-0.9984$ & $<6.5$ & $8.0-10.0$ & $86-107$ & 32 \\
\hline $\mathrm{MSPE} / \mathrm{F}$ & $\mathrm{U} \& \mathrm{P}$ & $2.0-75.0$ & $0.9955-0.9956$ & $1.83-3.60$ & $0.85 \& 0.74$ & $79.4-90.4$ & This work \\
\hline
\end{tabular}

Ex. $=$ extraction method, SIA = sequential injection analysis, CM-LPME = carrier-mediated liquid phase microextraction, MIP-ex. = molecularly imprinted polymers extraction, $\mathrm{CZE}=$ capillary zone electrophoresis, $\mathrm{SPME}=$ solid phase microextraction, $\mathrm{F}=$ spectrofluorimetry, $\mathrm{P}=$ plasma, $\mathrm{U}=$ urine.

A unique pharmacokinetic study was performed by analyzing urine samples of a volunteer receiving a single oral dose of $20 \mathrm{mg}$ PRO tablet. Urine samples were collected between $0-12 \mathrm{~h}$ after administration and these collections were monitored for PRO. The commutative PRO amount found using the proposed method at different interval times, are shown in Fig. 8. The found concentrations were in the range of 10.5 to 36.7 ng $\mathrm{mL}^{-1}$ which was in accordance with values reported in the literature [12]. In this work about $0.54 \%$ of the PRO dose was excreted as the unmetabolized drug in a total volume of $0.5 \mathrm{~L}$ urine within $12 \mathrm{~h}$.

\section{Conclusions}

In this work, MSPE based on MNPs combined with spectrofluorimetry was successfully developed for the extraction and determination of PRO in human urine and plasma samples. The proposed method offers a simple, safe, sensitive, and inexpensive method for extraction and determination of PRO. Method validation using spiked real samples demonstrated that the

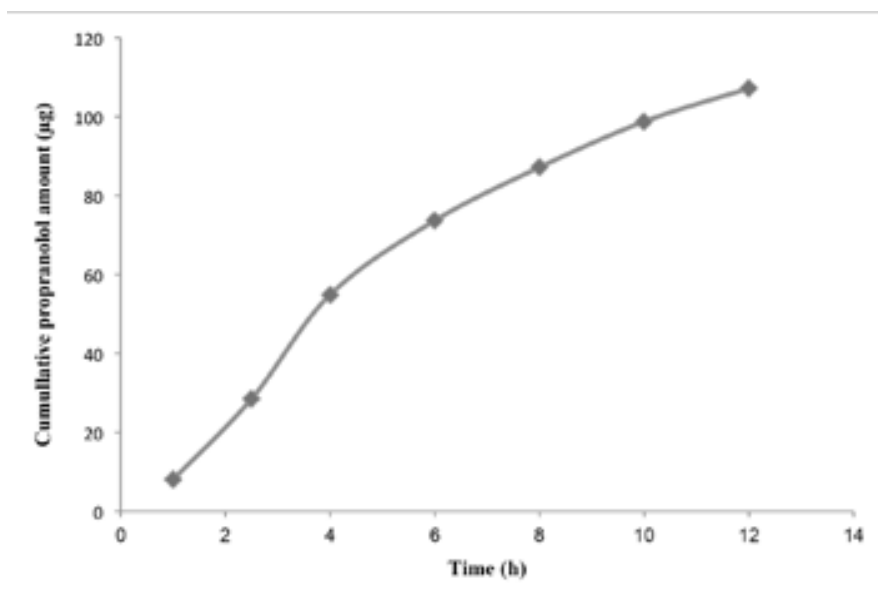

Fig. 8. Time course of excreted PRO levels through urine. method is capable of detecting trace PRO with adequate accuracy and precision. Also, sensitivity of the method is enough for the determination of PRO in urine and plasma samples. The proposed methodology possessed several advantages like simplicity and low cost, especially if more sophisticated techniques such as HPLC or GC are not available.

\section{Acknowledgements}

The authors are grateful to the Biotechnology Research Center of Tabriz University of Medical Sciences for Financial support and to Miss. S. Ahmadi for preparing FT-IR spectra.

The authors have declared no conflict of interest.

\section{References}

1. Silva, L. C.; Trevisan, M. G.; Poppi, R. J.; Sena, M. M. Anal. Chim. Acta 2007, 595, 282-288.

2. Fernández-Sánchez, J. F.; Segura Carretero, A.; Cruces-Blanco, C.; Fernández-Gutiérrez, A. J. Pharm. Biomed. Anal. 2003, 31, 859-865.

3. Partani, P. L.; Modhave, Y.; Gurule, S.; Khuroo, A.; Monif, T. J. Pharm. Biomed. Anal. 2009, 50, 966-976.

4. Kim, H. K.; Hong, J. H.; Park, M. S.; Kang, J. S.; Lee, M. H. Biomed. Chromatogr. 2001, 15, 539-545.

5. El-Saharty, Y.S. J. Pharm. Biomed. Anal. 2003, 33, 699-709.

6. Ismail, Z.; Abdul Wahab, M. S.; Abdul Rahman, A. R. Bur. J. Gen. Med. 2004, 1, 42-47.

7. Šatínský, D.; Serralheiro, H. S.; Solich, P.; Araújo, A. N.; Montenegro, Maria C.B.S.M. Anal. Chim. Acta 2007, 600, 122-128.

8. Zhang, L.; Su, X.; Zhang, C.; Ouyang, L.; Xie, Q.; Ma, M.; Yao, S. Talanta 2010, 82, 984-992.

9. Walle, T.; Oatis, J. E.; Walle, U. K.; Knapp, D. R. Drug Metabol. Dispos. 1982, 10, 122-127.

10. do Carmo Borges, N. C.; Modesto Rigato, H.; de Oliveira, P. R.; Rubert Nogueira, D.; Agnaldo Moreno, R.; Luiz Dalmora, S. J. Liq. Chromatogr. \& Rel. Technol. 2008, 31, $2927-2941$. 
11. Zhang, J.; Ding, L.; Wen, A.; Wu, F.; Sun, L.; Yang, L. Asian J. Pharm. Sci. 2009, 4, 169-177.

12. Berzas Nevado, J. J.; Rodríguez Flores, J.; Castaneda Penalvo, G.; Guzman Bernardo, F. J. Anal. Chim. Acta 2006, 559, 9-14.

13. Madrakian, T.; Afkhami, A.; Mohammadnejad, M. Talanta 2009 , 78, 1051-1055.

14. Jouyban, A.; Sorouraddin, M. H.; Farajzadeh, M. A.; Somi, M. H.; Fazeli-Bakhtiyari, R. Talanta 2015, 134, 681-689.

15. Yamini, Y.; Faraji, M. J. Pharmaceut. Anal. 2014, 4, 279-285.

16. Sun, L.; Chen, L.; Sun, X.; Du, X.; Yue, Y.; He, D.; Xu, H.; Zeng, Q.; Wang, H.; Ding, L. Chemosphere 2009, 77, 1306-1312.

17. Bagheri, H.; Zandi, O.; Aghakhani, A. Anal. Chim. Acta 2012, 716, 61-65.

18. Lizhao, X.; Shi, Y.; Cai, Y.; Mou, S. Environ. Sci. Technol. 2008, 42, 1201-1206.

19. Zhao, X.; Shi, Y.; Wang, T.; Cai, Y.; Jiang, G. J. Chromatogr. A 2008, 1188, 140-147.

20. Sun, L.; Zhang, C.; Chen, L.; Liu, J.; Jin, H.; Xu, H.; Ding, L. Anal. Chim. Acta 2009, 638, 162-168.

21. Huang, X. X.; Lu, J. Y.; Lai, H. F.; Wei, L. Q. J. Chin. Chem. Soc. 2015, 62, 52-58.

22. Mollahosseini, A.; Toghroli, M.; Kamankesh, M. J. Sep. Sci. 2015, $38,3750-3757$.
23. Bavili Tabrizi, A.; Rashidi, M. R.; Ostadi, H. J. Braz. Chem. Soc. 2014, 25, 709-715.

24. Tavakoli, M.; Shemirani, F.; Hajimahmoodi, M. Food Anal. Methods 2014, 7, 100-108.

25. Karimi, M. A.; Hatefi-Mehrjardi, A.; Mohadesi, A.; Mohammadi, S. Z.; Taghdiri, M.; Yarahmadi, J.; Mahmoodian, H.; Nezhad Khorasani, S. Iran. J. Anal. Chem. 2014, 1, 7-11.

26. Baghban, N.; Haji Shabani, A. M.; Dadfarnia, S. J. Chin. Chem. Soc., 2012, 59 (6), 782-787.

27. Faraji, M.; Yamini, Y.; Rezaee, M. Talanta 2010, 81, 831-836.

28. Bavili Tabrizi, A.; Naini, S.; Parnian, K.; Mohammadi, S.; Emami zad, F.; Pourtaghi Anvarian, S.; Abdollahi, A. Quim. Nova 2014, 37(7), 1182-1187.

29. Dominguez, A.; Fernandez, A.; Gonzalez, N.; Iglesias, E.; Montenegro, L. J. Chem. Educ. 1997, 74, 1227-1231.

30. FDA, Center for Drug Evaluation and Research, US Department of Health and Human Services, Guidance for Industry, Bioanalytical Method Validation, 2001.

31. Thompson, M.; Ellison, S. L. R.; Wood, R. Pure Appl. Chem. 2002, 74(5), 835-855.

32. Zhou, X.; Li, X.; Zeng, Z. J. Chromatogr. A 2006, 1104, 359-365. 